\title{
Fishing with bed nets on Lake Tanganyika: a randomized survey
}

\author{
Kate A McLean ${ }^{1 *}$, Aisha Byanaku', Augustine Kubikonse ${ }^{1}$, Vincent Tshowe ${ }^{1}$, Said Katensi ${ }^{2}$ and Amy G Lehman ${ }^{1}$
}

\begin{abstract}
Background: Malaria is among the most common causes of death along Lake Tanganyika, a problem which many aid organizations have attempted to combat through the distribution of free mosquito bed nets to high-risk communities. The Lake Tanganyika Floating Health Clinic (LTFHC), a health-based non-governmental organization (NGO), has observed residents of the Lake Tanganyika basin using bed nets to fish small fry near the shoreline, despite a series of laws that prohibit bed net use and other fine-gauge nets for fishing, implemented to protect the near-shore fish ecology. The LTFHC sought to quantify the sources of bed nets and whether they were being used for fishing.

Methods: The LTFHC conducted a survey of seven lakeside villages in Lagosa Ward, Tanzania. The government has divided each village into two to six pre-existing geographic sub-villages depending on population size. Seven households per sub-village were chosen at random for survey administration. The survey consisted of 23 questions regarding mosquito bed net practices, including the use of bed nets for fishing, as well as questions pertaining to any perceived changes to the fish supply.

Results: A total of 196 surveys were administered over a four-week period with a 100\% response rate. Over 87\% of households surveyed have used a mosquito bed net for fishing at some point. The majority of respondents reported receiving their bed net for free (96.4\%), observing "many" residents of their village using bed nets for fishing (97.4\%), and noticing a subjective decrease in the fish supply over time (64.9\%).

Conclusions: The findings of this study raise concerns that the use of free malaria bed nets for fishing is widespread along Lake Tanganyika, and that this dynamic will have an adverse effect on fish ecology. Further studies are indicated to fully define the scope of bed net misuse and the effects of alternative vector control strategies in water-based communities.
\end{abstract}

Keywords: Malaria, Insecticide-treated nets, Lake Tanganyika, Bed net misuse, Fishing, Ecology, Fisheries management

\section{Background}

Malaria is one of the most significant health problems in the world, with 207 million cases and 627,000 deaths per year, the majority of which occur in sub-Saharan Africa [1]. The use of insecticide-treated nets and long-lasting, insecticide-treated nets (ITNs and LLINs) can reduce malaria morbidity and mortality, particularly among children and pregnant women [2,3]. While these nets are intended by humanitarian donors to be used over sleeping spaces, there have been a number of reports of

\footnotetext{
* Correspondence: kate@floatingclinic.org

'Lake Tanganyika Floating Health Clinic, Kigoma, Tanzania

Full list of author information is available at the end of the article
}

misuse of nets for fishing [4-6], to make wedding dresses and veils [7] and to cover crops [8]. There is very little in the scientific literature addressing these trends, and what has been published suggests that misuse has not been adequately quantified and may even be a trivial problem [9].

The LTFHC has a full-time team on the shores of Lake Tanganyika, placing staff members in unique position to observe patterns of bed net use in lakeside communities where malaria is endemic $[10,11]$. Lake Tanganyika is the second largest freshwater lake in the world, with an area of 32,900 sq km, and a depth of 1,433 m [12]. Similar to the rest of Tanzania, the most common vector in the 
area is Anopheles gambiae [13], and although there have been studies in Tanzania suggesting An. gambiae resistance to insecticides [14], there has not been confirmation of this specifically along Lake Tanganyika. ITN distribution in Tanzania began in 2004-2005, with LLINs becoming more universally used by 2011 [15]. The Tanzanian Government has developed a subsidy/voucher scheme, with rates of LLIN use reported to be up to $75 \%$ in some regions as of 2011 [16]. Thus, it is unsurprising that bed nets are the primary means of vector control along the Lake. However, the rates of malaria prevalence among children in Kigoma Region, which is along Lake Tanganyika, remain the second highest in Tanzania at 26\% [10]. This is unchanged since 2007 [17], suggesting that bed net distribution has not had the intended effect.

The average annual income in Tanzania is US\$630, with the majority of the poor living in rural areas such as those along Lake Tanganyika [18]. These communities primarily subsist on fishing for Stolothrissa tanganicae and Luciolates stappersii, which typically range from 6.4 to $21.8 \mathrm{~cm}$ when caught [19]. Annually, over 200,000 tons of fish are harvested from Lake Tanganyika [20] and fishing nets are usually obtained from commercial sources and cost around US\$25. Tanzanian law currently prohibits the use of bed nets and other fine-gauge nets for fishing given the potential for harm to the fish supply through removal of fish fry [21]. There is growing concern among experts regarding increased illegal selling of these fish fry and the effect this could have on Lake Tanganyika's fish supply [22]. Additionally, Article 7 of the Convention on Sustainable Management of Lake Tanganyika, signed by all four riparian countries surrounding the Lake, directs the contracting states to establish a framework fisheries management plan. This management plan is intended to develop and implement harmonized national fisheries policies and regulations, and to promote community participation in fisheries management. Despite this, LTFHC noted multiple villages in Tanzania and the Democratic Republic of Congo using bed nets to fish (Figures 1 and 2), leading the team to hypothesize that this is a common practice along Lake Tanganyika. Exploration of this hypothesis has far-reaching implications, given that alternative bed net use has also been noted outside of sub-Saharan Africa [23].

\section{Methods}

The LTFHC conducted a randomized survey of seven villages in Lagosa Ward (Additional file 1) in western Tanzania along Lake Tanganyika: Igalula, Buhingu, Rukoma, Kalilani, Mgambazi, Katumbi, and Nkonkwa (Additional file 2). This region was chosen due to logistic feasibility, but also because the LTFHC has a partnership with the Green World Vision, whose staff are well known in this area. The team believed having the survey carried

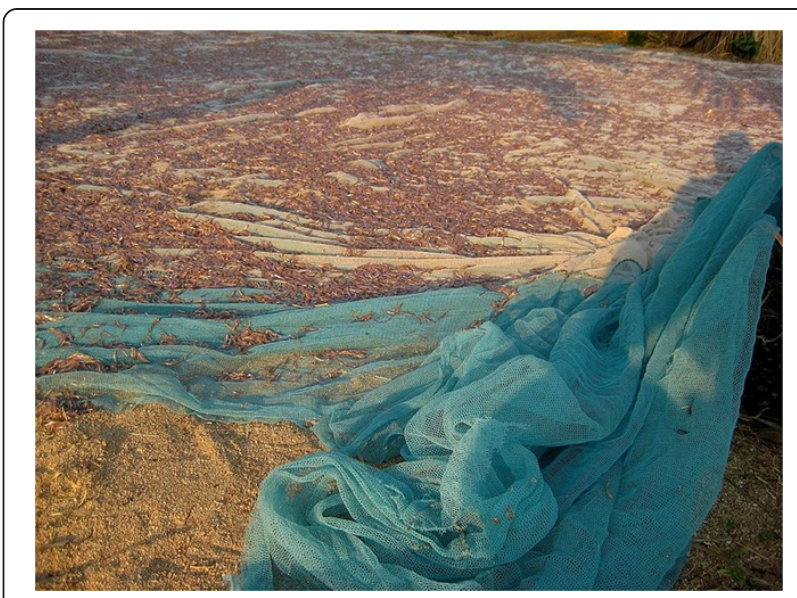

Figure 1 Bed nets used for fishing along Lake Tanganyika.

out by people who could easily foster community trust and openness through commonality of tribe and language would lead to the most thorough results. According to local officials, these villages have a total population of 40,805 . The government has divided each village into two to six pre-existing geographic sub-villages, depending on population size. We estimated a sample size of at least 150 based on the total population given above, a 95\% confidence level, an $8 \%$ margin of error, and a response distribution of $50 \%$ for the proportion of households using bed nets for fishing. Seven households per sub-village were therefore randomly chosen, through the Random Walk Method [24] for survey administration by the field team. The survey consisted of 23 questions regarding mosquito bed net practices, including the use of bed nets for fishing, as well as questions regarding the participants' perception of any changes to the fish supply. (Examples of survey questions are as follows: Do you ever use a bed net for fishing? If you use a bed net for fishing, how often do you do so? Have you ever seen anyone else using a bed net for fishing? If so,

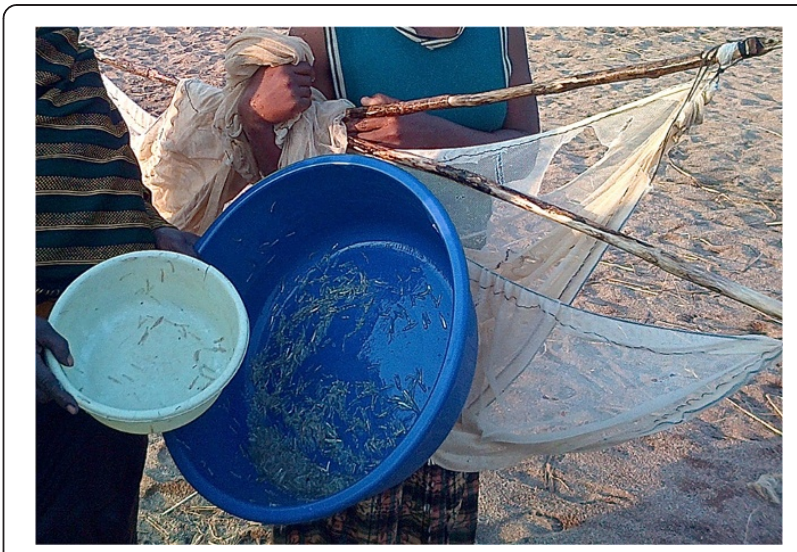

Figure 2 Fish fry caught in Lake Tanganyika with a bed net. 
how many people have you seen? Have you noticed any changes to the fish supply in Lake Tanganyika over time?) Surveys were written and administered by native speakers in Swahili, which is the most commonly spoken language in the region. No compensation was given for participation and it was made clear that participation was completely voluntary. The Green World Vision is a registered NGO in Tanzania and has governmental approval to conduct research related to natural resources management, community development and ecology. Statistical analysis was performed using STATA 13.1 (College Station, Texas, USA). In order to examine whether poverty predisposed using a bed net to fish, the number of children in a household was used as a proxy for socioeconomic status. This decision was based on a previous body of work suggesting negative economic consequences are linked to high birth rates [25-27]. Logistic regression was performed to explore this association.

\section{Results}

A total of 196 surveys were administered over a fourweek period in November 2013, with a 100\% response rate. This high response rate was attributed to the fact that those performing the survey were well known to and trusted by the community. On average, each household surveyed had 5.7 members (95\% CI 5.4-6.0), with 3.3 children (95\% CI 3.0-3.5) (Table 1). All households reported owning a bed net at some point in time, with the median ownership duration of six to 12 months (minimum less than six months, maximum over five years). The majority (189 (96.4\%, 95\% CI 92.5-98.4\%)) reported obtaining that bed net from an NGO at no cost. Those who paid for their bed nets spent an average of 5,100 TSH (95\% CI 4,307-5,818 TSH, approximately US\$3). A total of 171 households (87.2\%, 95\% CI 83.6-90.3\%) (Table 2) reported having ever used a bed net to fish, and 107 (62.6\% of those fishing with a bed net, 95\% CI 52.8-67.4\%) reported doing so more than once per day, over a previous period averaging six to 12 months.

All but one respondent (170/171, 99.4\% of those fishing with a bed net, 95\% CI 98.3-100.0\%) reported using the

Table 1 Survey population demographics

\begin{tabular}{ll}
\hline Household characteristics & Mean $(\mathbf{n}=\mathbf{1 9 6})$ \\
\hline Age of respondent & $34.2(95 \% \mathrm{Cl} 31.6-36.9)$ \\
Occupation: fishing & $13(6.6 \%)$ \\
Occupation: farming & $52(26.5 \%)$ \\
Occupation: fishing and farming & $131(66.8 \%)$ \\
Number of people in household & $5.7(95 \% \mathrm{Cl} 5.4-6.0)$ \\
Number of children & $3.3(95 \% \mathrm{Cl} 3.0-3.5)$ \\
Number of children under age 5 & $1.2(95 \% \mathrm{Cl} 1.1-1.3)$ \\
\hline
\end{tabular}

Table 2 Percentage of households that have fished with bed nets, by village

\begin{tabular}{lll}
\hline Village name & Number surveyed & Fish with bed nets (\%) \\
\hline Igalula & 35 & $31(88.6 \%)$ \\
Buhingu & 35 & $29(82.9 \%)$ \\
Rukoma & 28 & $25(89.3 \%)$ \\
Kalilani & 28 & $24(85.7 \%)$ \\
Mgambazi & 28 & $25(89.3 \%)$ \\
Katumbi & 28 & $24(85.7 \%)$ \\
Nkonkwa & 14 & $13(92.9 \%)$ \\
Total & $\mathbf{1 9 6}$ & $\mathbf{1 7 1 ( 8 7 . 2 \% )}$ \\
\hline
\end{tabular}

bed net to catch fish fry at the lakeshore, as opposed to using it for offshore fishing from a boat. The most frequent reason (46.8\%, 95\% CI 38.5-53.5\%) given for fishing with bed nets was needing a fishing net to generate income but being unable to afford one, with hunger as the second most reported reason (38.0\%, 95\% CI 29.5-44.0\%). Respondents were near unanimous (191 (97.4\%, 95\% CI 95.3-99.7\%)) in reporting seeing "many" others in their village use bed nets to fish. Most of those surveyed (170 (86.7\%, 95\% CI 82.0-91.6\%)) admitted awareness that fishing with bed nets is illegal in Tanzania. Although a trend was seen in this direction, logistic regression did not show a statistically significant association between having a higher number of children (and therefore more people to feed) and fishing with bed nets $(\mathrm{p}=0.069)$. One-hundred and eleven households (64.9\% of those fishing with a bed net, 95\% CI 56.9-71.1\%) reported a subjective decrease in the fish supply in Lake Tanganyika.

\section{Discussion}

This study suggests that the use of bed nets for fishing is a widespread, frequent and commonly accepted practice along Lake Tanganyika. This observation raises concerns that this practice may also be occurring in other waterside communities in sub-Saharan Africa. A previous study has suggested similar problems on Lake Victoria [28], however no large-scale studies have been published to date on this issue. The LTFHC is troubled by the revelations of this study for the following reasons: not only does the use of bed nets for fishing suggest they are not being used for the intended purpose of malaria prevention, but this practice may actively be harmful in other ways. For example, 12 million residents in the Lake Tanganyika basin depend on fish as their primary source of dietary protein [29]. Fishing with fine-gauge nets is already outlawed in Tanzania for fear that removal of fish fry will decimate these important fish populations. In addition, insecticides used to treat bed nets, such as permethrin, are 
known to be toxic to aquatic life [30]. Permethrin is moderately soluble in water, creating the possibility that fishing with bed nets could lead to leaching of this chemical into the lake, and subsequent damage to surrounding fish. Lake Tanganyika is home to over 300 fish species, twothirds of which are endemic [19], making this a potential danger to biodiversity. Permethrin is also classified by the Environmental Protection Agency as "likely to be carcinogenic to humans" [30], which poses a threat to residents in the villages surveyed, as they depend on the Lake for their drinking water.

There are likely complex motivating factors related to how bed nets are used within households. Previous research has shown that the poorest levels of society have the highest rates of parasitaemia in the region and are also the least likely to sleep under bed nets [31], however these same families are also battling other serious concerns, such as hunger. Economic pressures are known to impact malaria prevention [32], so it is certainly possible that behavioural change will not occur until either those pressures decrease (i.e., food security improves and hunger is less prevalent) or those pressures are disengaged from bed net use. This could mean changing standard vector control from bed nets, which are easy to mobilize for other uses, to something stationary, such as wall treatments or newly developed, individual spatial repellents.

\section{Conclusions}

When considered as a whole, examining bed net use for fishing sheds light on a range of issues: malaria mortality, food security, biodiversity, and preservation of safe water sources. As such, it is crucial for the international community to explore this issue further. More rigorous studies of the effects of fishing with bed nets on the fish supply and water quality are needed, as well as investigations of alternative personal vector control methods. NGO bed net distributors should also make every effort to assure proper bed net use. Additional community education regarding appropriate bed net use and the dangers of using those nets for fishing may be worth considering, as is the organization of behavioural change communication campaigns, which have been shown to be effective in addressing other public health problems [33]. The LTFHC conducted a widespread bed net distribution along Lake Tanganyika in the Democratic Republic of Congo with concurrent education and specific discussion of the laws prohibiting fishing. When staff returned to all health areas that received nets, they found bed net fishing in only a single village. These staff members personally confiscated the nets used for fishing, as the LTFHC does not wish to facilitate illegal activity. The effectiveness of such a strategy could also be studied going forward.

\section{Additional files}

\section{Additional file 1: Map 1 Lagosa Ward and Lake Tanganyika.}

Additional file 2: Map 2 Villages surveyed.

\section{Competing interests}

The authors declare that they have no competing interests.

\section{Authors' contributions}

$A B, A K, V T$, and $A G L$ conceived the study and helped to develop the hypothesis through direct observation of bed net use along Lake Tanganyika. KAM designed the study, including the survey, and completed the statistical analysis. SK administered the survey. All authors have contributed to, seen, and approved the final, submitted version of the manuscript.

\section{Acknowledgements}

We would like to thank Mark Grabowski from the Alliance for Malaria Prevention for advising during the study and analysis period.

\section{Author details}

${ }^{1}$ Lake Tanganyika Floating Health Clinic, Kigoma, Tanzania. ${ }^{2}$ The Green World Vision, Kigoma, Tanzania.

Received: 24 July 2014 Accepted: 30 September 2014

Published: 7 October 2014

\section{References}

1. WHO: World Malaria Report. Geneva: World Health Organization; 2013. http://www.who.int/malaria/media/world_malaria_report_2013/en/.

2. Lengeler $C$ : Insecticide-treated bed nets and curtains for preventing malaria. Cochrane Database Syst Rev 2004, 2:CD000363.

3. Gamble $C L$, Ekwaru JP, ter Kuile FO: Insecticide-treated nets for preventing malaria in pregnancy. Cochrane Database Syst Rev 2009, 2:1-51.

4. Lusaka Times: Don't Use Mosquito Nets To Catch Fish. http://www.lusakatimes. com/2008/04/25/don\%E2\%80\%99t-use-mosquito-nets-to-catch-fish/.

5. Butunyi C, Oloo E: Alarm as residents turn mosquito nets into fishing gear, The Daily Nation. Nation Media Group: Nairobi; 2008.

6. Zulu W: Zambia: Malaria Claims Over 50,000 Lives Yearly in the Average. Oslo: API/APN: African Press International; 2007.

7. Odeke A: Love Bug Craze Hits Uganda. BBC News. Edited by World Edition. London: BBC; 2002.

8. Fofanah M: Sierra Leone: (Misused) Key To Malaria Prevention. Rome: Inter Press Service New Agency; 2010. Inter Press Service New Agency.

9. Eisele TP, Thwing J, Keating J: Claims about the misuse of insecticide-treated mosquito nets: are these evidence-based? PLoS Med 2011, 8:e1001019.

10. 2011-12 Tanzania HIV/AIDS and Malaria Indicator Survey. http://nbs.go. tz/takwimu/this2012/MalariaFactsheet.pdf.

11. Democratic Republic of the Congo: WHO Health Profile. http://www.who.int/ gho/countries/cod.pdf?ua=1.

12. Lakes in Zambia. http://www.zambiatourism.com/destinations/lakes/laketanganyika.

13. Govella NJ, Chaki PP, Geissbuhler Y, Kannady K, Okumu F, Charlwood JD, Anderson RA, Killeen GF: A new tent trap for sampling exophagic and endophagic members of the Anopheles gambiae complex. Malar J 2009, 8:157.

14. Nkva TE, Akhouavri I, Poupardin R, Batengana B, Mosha F, Magesa S, Kisinza W, David JP: Insecticide resistance mechanisms associated with different environments in the malaria vector Anopheles gambiae: a case study in Tanzania. Malar J 2014, 13:28.

15. West PA, Protopopoff N, Rowland M, Cumming E, Rand A, Drakeley C, Wright A, Kivaju Z, Kirby M, Mosha FW, Kisinza W, Kleinschmidt I: Malaria risk factors in North West Tanzania: the effect of spraying, nets and wealth. PLoS One 2013, 8:e65787.

16. Eze IC, Kramer K, Msengwa A, Mandike R, Lengeler C: Mass distribution of free insecticide-treated nets do not interfere with continuous net distribution in Tanzania. Malar J 2014, 13:196

17. Malaria Operation Plan (MOP), Tanzania. http://reliefweb.int/sites/reliefweb. int/files/resources/83A08D626B53BCCA492577FA000DE190-Full_Report.pdf.

18. World Bank Data, Tanzania. http://data.worldbank.org/country/tanzania. 
19. Petit P, Shipton T: IUU Fishing on Lake Tanganyika. In Programme for the Implementation of a Regional Fisheries Strategy for the Eastern and Southern Africa and Indian Ocean Region; 2012. SF/2012/15.

20. Tierney JE, Mayes MT, Meyer N, Johnson C, Swarzenski PW, Cohen AS, Russell JM: Late-twentieth-century warming in lake Tanganyika unprecedented since AD 500. Nat Geosci 2010, 3:422-425.

21. Mushagalusa CD, Nshombo M, Lushombo: Littoral fisheries on Cichlidae (Pisces) from the northwestern part of Lake Tanganyika, East Africa. Aquat Ecosyst Health Manage 2014, 17(1):41-51.

22. Iwacu English News: Fishing Baby Fish "Umugara" Prevents Fish Multiplication in Lake Tanganyika. http://www.iwacu-burundi.org/blogs/ english/fishing-baby-fish-umugara-prevents-fish-multiplication-in-laketanganyika/.

23. Lover AA, Sutton BA, Asy AJ, Wilder-Smith A: An exploratory study of treated-bed nets in Timor-Leste: patterns of intended and alternative usage. Malar J 2011, 10:199.

24. Unicef Data. http://www.childinfo.org/files/chap06.pdf.

25. United Nations in Tanzania: United Nations in Tanzania. http://tz.one.un. org/index.php/what-we-do/health-and-nutrition.

26. Enke S: The economic case for birth control in underdeveloped nations. Challenge 1967, 15:30-31.

27. Canning D, Schultz TP: The economic consequences of reproductive health and family planning. Lancet 2012, 380:165-171.

28. Minakawa N, Dida G, Sonye G, Futami K, Kaneko S: Unforeseen misuses of bed nets in fishing villages along Lake Victoria. Malar J 2008, 7:165.

29. Mwina H: The Strategic Action Program for the Protection of Biodiversity and Sustainable Management of Natural Resources in Lake Tanganyika, Lake Tanganyika Authority in partnership with UNDP, GEF, and the Global Environment Facility; 2011.

30. Environmental Protection Agency: Permethrin Facts (RED Fact Sheet). http://www.epa.gov/oppsrrd1/REDs/factsheets/permethrin_fs.htm\#uses.

31. WHO/UNICEF: Africa Malaria Report. Geneva: World Health Organization; 2003.

32. Stratton L, O'Neill MS, Kruk ME, Bell ML: The persistent problem of malaria: addressing the fundamental causes of a global killer. Soc Sci Med 2008, 67:854-862.

33. Family Health International: Behavior Change Communication (BCC) Campaigns. http://www.aidsdatahub.org/sites/default/files/documents/ Behavior_Change_Communication_(BCC)_Campaigns_in_Vietnam.pdf.pdf.

doi:10.1186/1475-2875-13-395

Cite this article as: McLean et al.: Fishing with bed nets on Lake

Tanganyika: a randomized survey. Malaria Journal 2014 13:395.

\section{Submit your next manuscript to BioMed Central and take full advantage of:}

- Convenient online submission

- Thorough peer review

- No space constraints or color figure charges

- Immediate publication on acceptance

- Inclusion in PubMed, CAS, Scopus and Google Scholar

- Research which is freely available for redistribution 